\title{
Characterization of Marble-Clay Composite as Alternative To Conventional Bricks in Building
}

\section{ALABI, AB; UTHMAN, YB; *AKINSOLA, SI; OSANYINLUSI, O}

\author{
Department of Physics, University of Ilorin, Ilorin, Nigeria. \\ *Corresponding Author Email: siakinsola711@gmail.com; +234816-660-2544 /08024208631
}

\begin{abstract}
The usability of marble as an additive material with clay in industrial brick has been investigated. Marble was collected from the marble deposit located at Igbeti (latitude $8^{0} 45^{1}$ longitude $4^{0} 8^{1}$ E.), and the red clay was collected at University of Ilorin, Ilorin (latitude $8^{0} 32^{1} \mathrm{~N}$ and longitude $4^{0} 34^{1} \mathrm{E}$ ), both in Nigeria. Marble and Clay were processed for the preparation of the composite. The two materials were mixed in varying proportion of marble, ranging from 0 wt. $\%$ to $45 \%$. The mixture was made into bricks with size 6.0 x 7.0 x $2.0 \mathrm{~cm}$. Ten sample bricks of different marble composition were prepared. These bricks were compressed and heated at a temperature of $950{ }^{\circ} \mathrm{C}$ for 2 hours. Water absorption and thermal conductivity tests were carried out on the samples. It was observed that the amount of marble added had positive effect on the physical and mechanical strength of the produced brick. The results also show that increase in percentage of marble will be of good advantage in keeping the house warm during raining season as observed from the thermal conductivity test.
\end{abstract}

\section{DOI: https://dx.doi.org/10.4314/jasem.v22i9.24}

Copyright: Copyright $\odot 2018$ Alabi et al. This is an open access article distributed under the Creative Commons Attribution License (CCL), which permits unrestricted use, distribution, and reproduction in any medium, provided the original work is properly cited.

Dates: Received: 28 August 2018; Revised: 10 September 2018; Accepted: 30 September 2018

Keywords: Marble, Clay, Physico-mechanical, Thermal conductivity, Water Absorption

Building materials make up a key component in housing construction. Building materials constitute about $60-80$ percent of the entire cost of housing construction (http://schoolofestate.com). It has become increasingly glaring that most of the urban population live in de-humanizing housing environment while those that have access to average housing do so at abnormal cost (Ikechukwu and Iwuagwu, 2016). It would be excellent if these raw materials were abundantly available or they should be renewable in nature. It should be noted that excessive reliance on foreign and imported building materials is not the only contributing factor for increasing cost of buildings but also the transportation from urban areas to rural areas and vice versa especially in the face of this current fuel scarcity and hike in Nigeria (Ikechukwu and Iwuagwu, 2016). Clay is one of the best materials that one can use in order to build a sustainable construction. The clay is usually added to straw, sand, and then water in order to make bricks that are used as walls. These walls are not subject to becoming moist and breaking apart as there are still homes in Wales that maintain their structure after hundreds of years of rain. In addition to the use as a solid building material, it is also acceptable to use clay as an insulator to the weather. This will allow homes to maintain their heat during the harmattan months and maintain the comfortable temperatures during the rainy months. More importantly, it is a natural way to provide efficient energy, so buildings do not require too much energy in order to maintain the proper temperature. According to Sergio (2008), there are some technologies, which are also low cost and can take a number of forms. There is the use of very traditional materials (e.g. soil) utilised in a more efficient manner. Some use innovative composite materials based on local forestry resources, such as natural fibers and plant materials.

The aim of this work is to investigate the use of marble powder as additive in clay bricks and its effect on physical, mechanical and thermal properties of the clay- based bricks, seeking an optimum content of marble and minimizing its negative impact on the environment.

\section{MATERIALS AND METHODS}

In this study, the production of fired bricks from mixtures of brick clay and waste marble powder additive was accomplished. The marble and the clay were crushed into smaller particles in a laboratory to particle size smaller than $100 \mu \mathrm{m}$ after which they were further subjected to other pre-treatments such as drying, milling and sieving. The density of the raw materials was determined by taking their masses and 
volume using the weigh balance in the laboratory and measuring cylinder respectively.

Process of Production: The brick clay -without and with waste marble addition was prepared in a mechanical mixer. Mixture proportion was presented in Table 1 . The raw materials were manually mixed for $10 \mathrm{~min}$ to get a uniform consistency. After dry mixing, water was added in proportion to the raw materials of total weight and was sprayed to the powder mixtures for the production of semi-dry molded brick samples. A hydraulic press was used to make brick pellets with dimensions $7 \mathrm{~cm}$ x $6 \mathrm{~cm} \times 2 \mathrm{~cm}$. Semi-dry mixtures were compressed with a pressure of $40 \mathrm{Mpa}$ by turning the threaded screw by 20 turn. After shaping of bricks, they were left to dry in ambient conditions for 24 hours. The same processes were repeated for the entire sample. S1 to S10 signifies the sample numbers according to the proportion of the mixture. S1 has the lowest percentage of marble dust while S10 has the highest percentage. The samples were then fired using a laboratory-type electrical furnace to a temperature of $400{ }^{\circ} \mathrm{C}$ at $40.5^{\circ} \mathrm{C} / \mathrm{min}$, and thereafter to a temperature of $950{ }^{\circ} \mathrm{C}$ at $56.2{ }^{\circ} \mathrm{C} / \mathrm{min}$. The samples were left at this temperature for two hours in order to achieve strength. After firing, the three samples S8, S9 and S10 were observed to collapse because they have higher percentage of marble, and marble has a low "melting point"

Table 1: Proportion of Mixture of Clay and Marble powder

\begin{tabular}{llllllll}
\hline $\begin{array}{l}\text { Sample } \\
\text { Number }\end{array}$ & $\begin{array}{l}\text { Clay (vol.) } \\
\mathrm{cm}^{3}\end{array}$ & $\begin{array}{l}\text { Marble } \\
\left(\text { vol. } \mathrm{cm}^{3}\right.\end{array}$ & $\begin{array}{l}\text { Clay } \\
(\mathrm{wt}) \mathrm{g}\end{array}$ & $\begin{array}{l}\text { Marble } \\
(\mathrm{wt}) \mathrm{g}\end{array}$ & $\begin{array}{l}\text { Clay } \\
(\%)\end{array}$ & $\begin{array}{l}\text { Marble } \\
(\%)\end{array}$ & $\begin{array}{l}\text { Water } \\
\text { absorption unit }\end{array}$ \\
\hline S1 & 84.0 & 0 & 93.49 & 0 & 100 & 0 & 50 \\
S2 & 79.8 & 4.2 & 88.82 & 5.88 & 95 & 5 & 47 \\
S3 & 71.4 & 12.6 & 79.47 & 17.64 & 90 & 10 & 43 \\
S4 & 67.2 & 16.8 & 74.79 & 23.52 & 85 & 15 & 34 \\
S5 & 63 & 21 & 70.12 & 29.40 & 80 & 20 & 32 \\
S6 & 58.8 & 25.2 & 65.44 & 35.28 & 75 & 25 & 31 \\
S7 & 54.6 & 29.4 & 60.77 & 41.16 & 70 & 30 & 26 \\
S8 & 50.4 & 33.6 & 56.10 & 47.04 & 65 & 35 & 25 \\
S9 & 46.2 & 37.8 & 51.42 & 52.92 & 60 & 40 & 23 \\
S10 & 42 & 42 & 46.75 & 58.80 & 55 & 45 & 21 \\
\hline
\end{tabular}

\section{RESULTS AND DISCUSSION}

Temperature is a measure of the ability of a substance, or more generally of any physical system, to transfer heat energy to another physical system. The higher the temperature of an object, the greater the tendency of that object to transfer heat. The lower the temperature of an object, the greater the tendency of that object to be on the receiving end of the heat transfer. Change in temperature, $\Delta \mathrm{T}$ is the difference between the final temperature and the initial temperature. That is, $\Delta \mathrm{T}=$ $\mathrm{T}_{\mathrm{f}}-\mathrm{T}_{\mathrm{i}}$. According to the results shown in table 2 , the decrease in temperature difference with percentage increase of marble means cooling and increase in temperature difference means warming. Thermal conductivity results of the bricks produced are shown in Table 2.

Table 2: Thermal conductivity results of the prepared composite samples

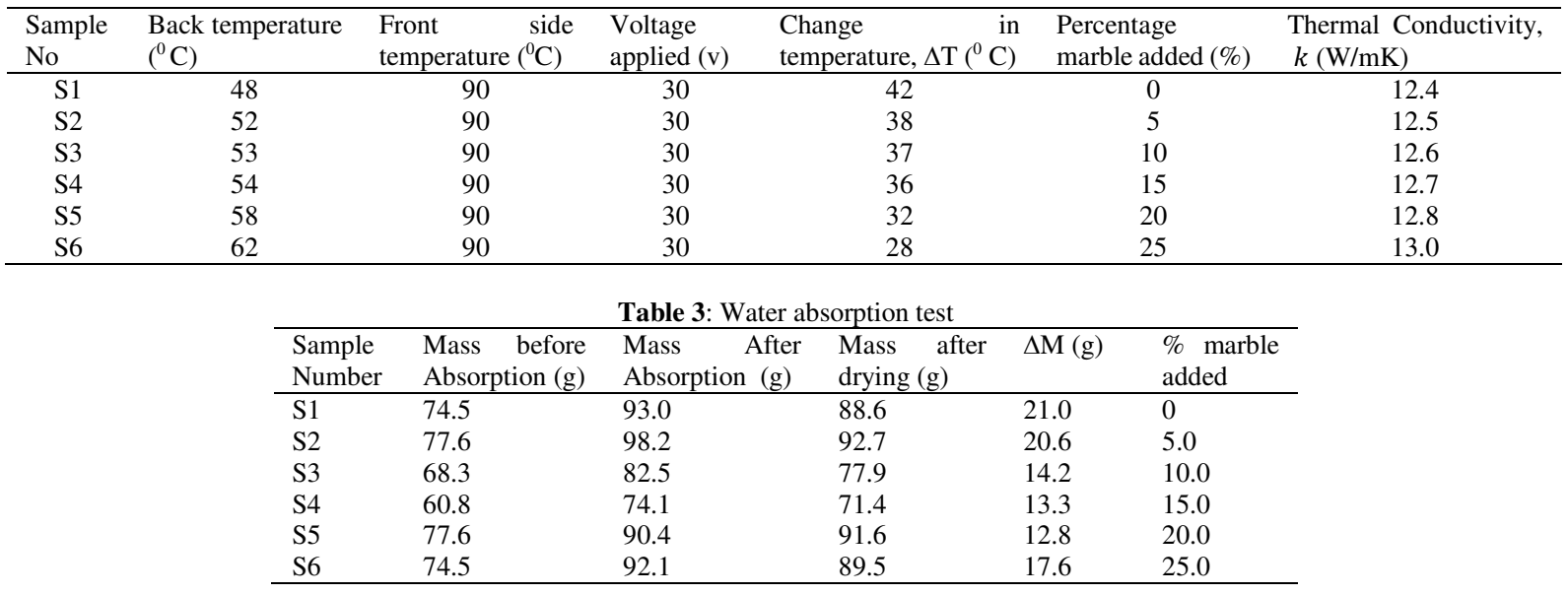


Thermal conductivity is a material property describing the ability to conduct heat. Thermal conductivity can be defined as the quantity of heat transmitted through a unit thickness of a material in a direction normal to a surface of unit area due to a unit temperature gradient under steady state conditions. The thermal conductivity ( $\boldsymbol{\lambda}$ or $\mathbf{k})$, was estimated by equation 1 .

$$
\mathrm{k}=\frac{Q L}{A \Delta \mathrm{T}}
$$

where, thermal conductivity is $\mathbf{k}$ in $\mathbf{W} / \mathbf{m} \mathbf{K}$, the amount of heat transfer through the material is $\mathbf{Q}$ in $\mathbf{J} / \mathbf{S}$ or $\mathbf{W}$, the area of the body is $\mathbf{A}$ in $\mathbf{m}^{2}$, the difference in temperature is $\Delta \mathrm{T}$ in $\mathbf{K}, \mathrm{L}$ is the length of the body, $\Delta \mathrm{T}$ is the difference in front side temperature and back side temperature in $\mathrm{K}$. The value of $\mathrm{Q}$ is estimated by equation 2 .

$$
Q=m C \Delta T
$$

Where $\mathrm{m}$ is the mass of sample, $\mathrm{C}$ is the specific heat capacity and $\Delta \mathrm{T}$ is the temperature difference, $\mathrm{C}=$ $0.92 \mathrm{~J} / \mathrm{g} / \mathrm{K}$ (for the composite, which is near that of a marble $)$ and $\Delta \mathrm{T}=37^{\circ} \mathrm{C}($ an example for sample $\mathrm{S} 3)=$ $310 \mathrm{~K}$

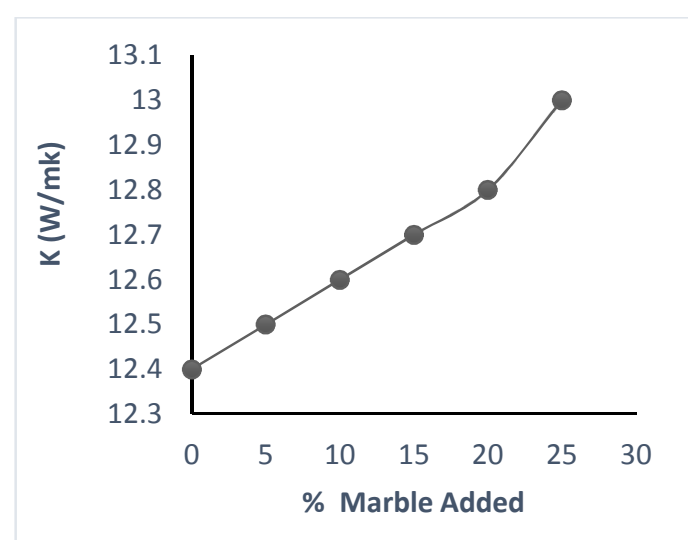

Fig.1: Variation of thermal conductivity with the percentage of marble in samples

The thermal conductivity of the samples showed an increase depending on the amount of marble incorporated into the clay brick mixture up to $25 \%$. Fig. 1 shows that the thermal conductivity increases as the percentage of marble powder increase. The thermal conductivity is at highest when the ratio of marble to clay was at $75: 25$ which is; $25.20 \mathrm{~g}: 65.44 \mathrm{~g}$ respectively. The result of this test shows that the cost of generating energy for warming up a building could be reduced. The brick samples were immersed in water for 13 hours to determine the absorption rate of the sample according to the percentage mixture of the clay and marble powder.

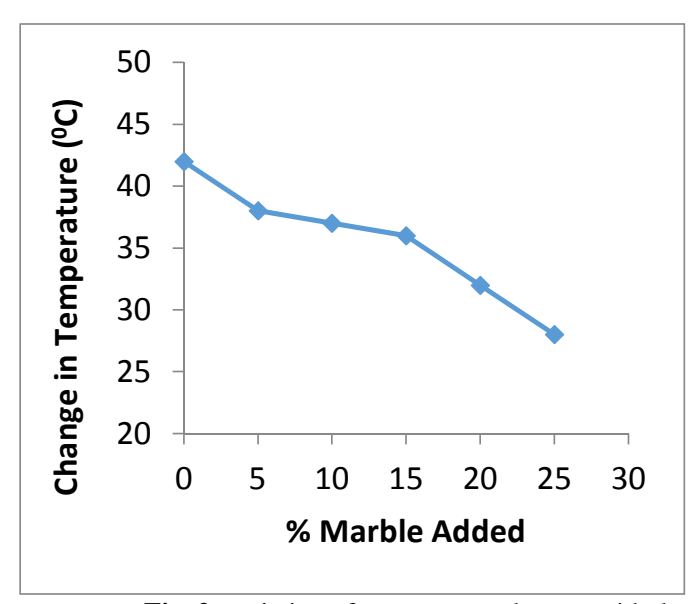

Fig. 2: variation of temperature changes with the percentage of marble added.

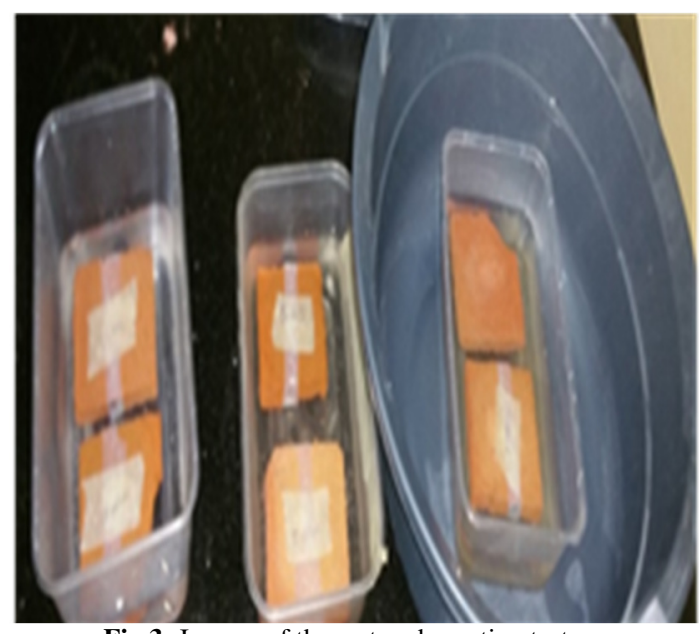

Fig 3: Images of the water absorption test process.

The mass of the samples, before the absorption test, after the absorption test and after drying the samples in an ambient temperature for 24 hours were recorded. Water absorption test of the produced sample bricks were presented in table 3 . As seen from table 3 , the lowest water absorption value was obtained in S4 which has the lowest porosity and highest bulk density.

The highest water absorption value was seen in S2 which has the lowest porosity and bulk density. This observation connotes a close relationship between water absorption, porosity and bulk density of bricks. Also, percentage of marble has significant influence on the water absorption of bricks (as shown in fig. 4) because waste marble addition increases significantly the porosities of bricks at both temperatures. 
$\Delta \mathrm{M}$ is the quantity of water absorbed, and increase in $\Delta \mathrm{M}$ implies high porosity, decrease in $\Delta \mathrm{M}$ implies low porosity.

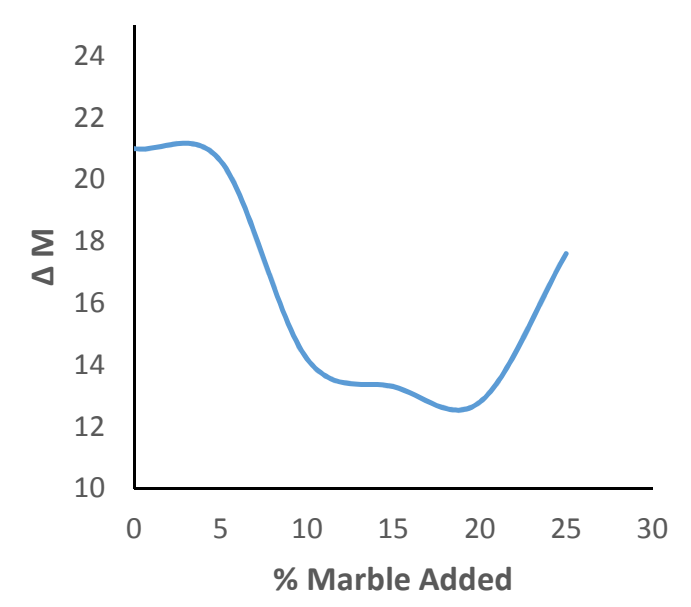

Fig. 4: Quantity of water absorbed $\Delta \mathrm{M}(\mathrm{g})$ against the percentage of marble added
Conclusion: The investigations reveal that increase in marble percentage results in increase in water absorption and hence decreases the mechanical properties. With increasing demands of the construction industry, bricks quality and cost become more important day by day in Nigeria. This study has significant important role on recycling waste marble in the brick production along with great contributions to economy and ecology.

\section{REFERENCES}

Ikechukwu, O; Iwuagwu, BU. (2016).Traditional Building Materials as a Sustainable Resource and Material for Low Cost Housing in Nigeria: Advantages, Challenges and the Way Forward. Inter. J. Res. Chem. Metallurgic. Civil Engineer. 3 (2): 247-252.

Sergio, Meriani. (2008). Available technologies for local building materials. International centre for science and High Technology, Trieste. 